\title{
Articulações da praxiologia motriz com a Concepção Crítico-Emancipatória
}

\author{
Gil Teixeira Oliveira*
}

João Francisco Magno Ribas**

\begin{abstract}
Resumo: O presente trabalho consiste numa análise teórica conceitual da Praxiologia Motriz e da Concepção Crítico-Emancipatória, desenvolvendo e situando alguns elementos da Teoria da Ação Motriz, mantendo o compromisso com um ensino emancipador. Os resultados da investigação apontam para aproximações da praxiologia motriz no que tange à compreensão da lógica interna e criação de uma gramática dos jogos e esportes viabilizando o processo de entendimento do significado central do "movimentar-se", assim como na construção do "agir comunicativo".

Palavras-chave: Esporte. Sociologia: educação. Formação de conceitos. Competência profissional.
\end{abstract}

\section{CONSIDERAÇÕES INICIAIS}

Este texto apresenta as primeiras articulações de elementos da Praxiologia Motriz com orientações teórico-metodológicas da Concepção Crítico-Emancipatória. Trata-se, portanto, de realizar um debate entre essas duas temáticas, através de uma análise teórica conceitual. Entretanto, antes de nos aprofundarmos, apresentaremos alguns indícios que justificam a relevância, no momento, de um estudo mais detalhado.

Um primeiro ponto de aproximação encontrado neste estudo se refere ao conceito de esporte elaborado por Parlebas e às características de Esporte de Rendimento apontadas por Kunz. A caracterização de Esportes apresentada por Parlebas (1999, p. 197) está submetida à autoridade institucionalmente reconhecida; são regidos por regulamento mais preciso, confiado e reconhecido, profundamente atrelados

* Professor Especialista em Educação Física Escolar, Universidade Federal de Santa Maria. Santa Maria, RS, Brasil. E-mail: gil.ufsm@bol.com.br

** Doutor em Educação Motora pela UNICAMP e Professor Adjunto da Universidade Federal de Santa Maria. Santa Maria, RS, Brasil. E-mail: ribasjfm@uol.com.br 
aos processos socioeconômicos de produção e de consumo - sustentam que o mundo do esporte institucionalizado, chamado por Kunz de Esporte de Rendimento, fomenta princípios de sobrepujança e de comparações objetivas, formas essas que não deverão entrar na escola sem uma transformação pedagógica. Assim, Parlebas, com a definição de que denomina Esporte Institucionalizado, complementa a ideia de Kunz no que tange à definição de Esporte de Rendimento. Neste texto, trazemos conceitos centrais dessa metodologia, como: Transformação Didático-pedagógica (1994) e encenação esportiva, para determinar e aprofundar que consequências o conhecimento praxiológico tem em uma práxis para a competência crítica e emancipatória.

Essa transformação no ensino passa por uma mudança no sentido, individual e coletivo, dos esportes para democratizá-lo nas aulas, além da compreensão das concepções de movimento, de educação e de sociedade, implícitas na proposta da abordagem. Para transformar os esportes e jogos, é preciso conhecer e estudar os fundamentos e ações motrizes de cada modalidade, o que Parlebas denomina de Lógica Interna. Princípios e instrumentos da Praxiologia Motriz podem auxiliar nesse processo pois esse conhecimento se propõe a compreender a estrutura geral, os tipos de interação, as características essenciais, os processos de tomadas de decisões, entre outros conceitos que formam os Jogos Esportivos.

A Praxiologia Motriz não é uma concepção de ensino dos esportes, nem é sua pretensão se tornar uma. A maior parte dos estudos tem utilizado os instrumentos de análise para realizar descrições densas de fundamentos e de relações internas dos jogos e esportes, buscando desvelar este mundo, sem preocupações diretas com situações reais de ensino. Este artigo pretende avançar em um campo pouco explorado pela Praxiologia Motriz, que é a aproximação e relação com uma concepção de ensino, neste caso, com a Abordagem Crítico-Emancipatória.

O primeiro nível de reflexão que iremos propor trata de uma revisão da Concepção Crítico-Emancipatória e da Praxiologia Motriz em dois momentos intitulados, respectivamente, com o nome da área que abrangem. Poderíamos citar vários pontos importantes dessas temáticas mas tivemos que destacar alguns em função das limitações e

Movimento, Porto Alegre, v. 16, n. 01, p. 131-148, janeiro/março de 2010. 
do objetivo do trabalho, ou seja, encontrar os pontos de aproximação desses conhecimentos. Esse debate foi reservado para a última parte deste texto.

\section{A Abordagem Crítico-Emancipatória}

A Abordagem Crítico-Emancipatória, sistematizada pelo Professor Elenor Kunz, teve suas primeiras bases difundidas na obra "Ensino e Mudanças" (1991) e, mais tarde, em outro livro denominado "Transformação Didático-Pedagógica do Esporte" (1994), em que apresenta essa concepção pedagógica na intenção de estimular mudanças reais e concretas na prática pedagógica da Educação Física Escolar. O autor busca uma ampla reflexão sobre a possibilidade de ensinar os esportes pela sua transformação didático-pedagógica e de tornar o ensino escolar uma educação de crianças e jovens para a competência crítica e emancipada. Neste momento, iremos apontar alguns elementos básicos de entendimento desta abordagem - que possui grande acúmulo de conhecimento.

A metodologia Crítico-Emancipatória fundamentada por esses pressupostos se concretiza, segundo Kunz (2004), no desenvolvimento de três competências: a competência objetiva, que visa a desenvolver a autonomia dos alunos através da técnica; a competência social, referente aos conhecimentos e esclarecimentos que os alunos devem adquirir para entender o próprio contexto sociocultural; a competência comunicativa, que assume um processo reflexivo responsável por desencadear o pensamento crítico e ocorre através da linguagem, que pode ser de caráter verbal, escrito e/ou corporal.

Orientando o ensino para um processo de desconstrução de imagens negativas que o aluno interioriza na sua prática de esportes autoritários e domesticadores. Entendendo a emancipação como um processo contínuo de libertação do aluno das condições limitantes de suas capacidades racionais críticas e até mesmo o seu agir no contexto sociocultural e esportivo. O conceito crítico pode ser entendido como a capacidade de questionar e analisar as condições e a complexidade de diferentes realidades de forma fundamentada permitindo uma constante autoavaliação do envolvimento

Movimento, Porto Alegre, v. 16, n. 01, p. 131-148, janeiro/março de 2010. 
134 Artigos Originais Gil T. Oliveira e João Francisco M. Ribas

objetivo e subjetivo no plano individual e situacional (KUNZ apud BUSSO; VENDITTI, 2004, p. 3).

Em nome dessa emancipação por uma racionalidade comunicativa é que Elenor Kunz argumenta em favor de uma nova forma de ensino do esporte. Com a intenção de discernir os reais interesses dos falsos (criados ideologicamente pela sociedade), torna-se necessária uma compreensão do fenômeno esportivo em todas as suas dimensões e manifestações.

\begin{abstract}
Pela reflexão comunicativa e crítica, transcendem-se os limites das informações como forma de esclarecimento ou do conhecimento científico como verdades evidentes e inquestionáveis e somente com esta forma de esclarecimento se pode intencionar a emancipação humana e social, significando a superação das dependências e da menoridade (KUNZ, 2004).
\end{abstract}

Na elaboração e construção de planejamentos para a Educação Física Escolar, o esporte recebe destaque entre todos os outros elementos da "Cultura de Movimento". Contudo, vem sendo ensinado predominantemente de forma normatizada e visando a imitar os padrões do alto rendimento, seguindo suas normas e regras, mantendo-se nos limites que a técnica e a tática específicas das distintas modalidades esportivas exigem. Como consequência, ocorre a exclusão de um grande horizonte de atividades e movimentos de significativo valor sociocultural e educacional. Não se trata de negar completamente o esporte normativo enquanto manifestação sociocultural e, sim, apontar sua incoerência como prática escolar quando trabalhada de forma acrítica. Kunz, através de seus estudos, destaca dois princípios fundamentais do Esporte de Rendimento que demonstram a inviabilidade deste como possibilidade educacional. São eles:

O Princípio da Sobrepujança surge da aceitação da ideia de que qualquer um, qualquer equipe, tem a possibilidade de vencer em confrontos esportivos. O objetivo dos esportes fica assim reduzido à ideia de vencer constantemente, de sobrepujar o adversário ou a equipe adversária.

O Princípio das Comparações Objetivas surge justamente da necessidade de se oferecerem chances iguais a todos nas disputas esportivas. As conse-

Movimento, Porto Alegre, v. 16, n. 01, p. 131-148, janeiro/março de 2010. 


\begin{abstract}
quências são a padronização do espaço, locais de disputa, desenvolvimento de normas e regras universais para o esporte etc. Todo o trabalho de produção do rendimento esportivo exige a adequação das ações esportivas a estes espaços padronizados e às regras motoras bem rígidas (KUNZ, 1991, p. 110).
\end{abstract}

A pedagogia Crítico-Emancipatória transcende a mera instrumentalização técnica e possibilita uma melhor compreensão da forma de institucionalização e legitimação do esporte em nossa sociedade. Dessa forma, proporciona o entendimento, por parte dos alunos, de que o esporte nada mais é do que uma invenção social e não um fenômeno natural pois, sendo uma instituição socialmente construída, acaba reproduzindo as ideologias e imagens desse modelo social, alcançando, assim, melhor entendimento da realidade em que essa manifestação se insere.

O professor Elenor Kunz (2004) também acredita que as proposições metodológicas presentes neste processo de ensino possibilitam aos alunos uma permanente busca por soluções individuais e/ou coletivas, viabilizando o agir independente, a cooperação e a comunicação com o grupo e com o professor, adquirindo, assim, um saber de maior relevância para sua emancipação. O professor deverá promover o "agir comunicativo" entre seus alunos para expressar entendimentos do mundo social, subjetivo e objetivo e a interação nas tomadas de decisão, formulação de interesses e problematização do esporte e manifestações corporais. Para que através dessa reflexão e desse Agir Comunicativo possam transcender a capacidade técnica e instrumental e, assim, compreender a coerção autoimposta de que padecem, conseguindo, com isso, dissolver o poder ou a objetividade dessa coerção e assumindo um estado de maior liberdade e conhecimento de seus verdadeiros interesses, ou seja, esclarecimento e emancipação.

\title{
3A Praxiologia Motriz
}

A Praxiologia Motriz foi sistematizada pelo professor francês Pierre Parlebas que há mais de quarenta anos tem publicado diversos artigos, além de seis relevantes obras sobre o tema. Entre elas, a mais importante obra da área, conhecida também como Teoria da Ação Motriz, Jeux, Sports et Sociétes, lançada no ano de 1999.

Movimento, Porto Alegre, v. 16, n. 01, p. 131-148, janeiro/março de 2010. 
Nesse último livro, o autor define a Praxiologia Motriz como: "Ciência da Ação Motriz e especialmente das condições, modos de funcionamento e resultados de seu desenvolvimento." (PARLEBAS, 2001, p. 264). O tema vem sendo estudado na França, em Portugal e principalmente na Espanha, onde possui grande relevância no contexto acadêmico. No Brasil, encontramos três professores que trabalham com este referencial: no Rio de Janeiro, o professor José Ricardo da Silva Ramos, que no ano de 2000 realizou estágio em Praxiologia Motriz orientado pelo Professor Pierre Parlebas na Universidade René Descartes e em 2006 defendeu uma tese junto à Universidade Federal Fluminense, aprofundando-se na mesma temática; o professor Marco Bortoletto, em Campinas, que realizou o seu doutoramento junto ao Grupo de Estudos Praxiológicos (GEP) do Instituto Nacional de Educação Física da Catalunha, Centro de Lleida, Espanha e docente da UNICAMP e o professor João Francisco Magno Ribas, docente da UFSM, que realizou seu estudo de doutorado em conjunto com o mesmo grupo. Os três professores tematizaram suas teses com base no conhecimento praxiológico. Em 2003, temos a publicação da obra organizada pelo professor José Ricardo da Silva Ramos, intitulada "Praxiologia Motriz no Brasil", que apresentou os principais trabalhos produzidos na área e, mais recentemente, o professor João Francisco Magno Ribas publicou uma coletânea de textos de professores espanhóis, franceses e brasileiros intitulada "Jogos e esportes: fundamentos e reflexões da praxiologia motriz" (RIBAS, 2008).

Na obra recente intitulada Introdución a la Praxiologia Motriz, Lagardera Otero e Lavega Burgués explicam que

\footnotetext{
[...] a Praxiologia Motriz aspira a definir uma região epistemológica inédita no âmbito das práticas físicoesportivas. Queremos dizer, com isto, que no âmbito da ciência até o momento reconhecida e aceita não existe nenhuma outra disciplina que aborde o estudo do esporte deste prisma, como fenômeno de caráter ôntico. ${ }^{1}$ (LAGARDERA OTERO; LAVEGA BURGUÉS, 2003, p. 38)
}

\footnotetext{
${ }^{1}$ Existente; distinto ao ontológico que se refere ao ser categorial, ou seja, à essência ou à natureza do existente. Por exemplo, a propriedade empírica de um objeto é uma propriedade ôntica; a possibilidade ou a necessidade é uma propriedade ontológica (ABBAGNANO, 1983, p. 697).

Movimento, Porto Alegre, v. 16, n. 01, p. 131-148, janeiro/março de 2010.
} 
Para a Praxiologia Motriz, todo jogo esportivo constitui um Sistema Praxiológico, ${ }^{2}$ possuidor de uma ordem própria e uma estrutura única decorrente de uma lógica, a partir da qual as inúmeras ações de jogo adquirem sentido. As ações de jogo manifestam-se como um sistema em que vários componentes interagem entre si e que qualquer mudança nas características desses componentes modifica toda a dinâmica do sistema, ou seja, altera sua Lógica Interna. Pode-se, assim, afirmar que a Praxiologia Motriz é o estudo da Lógica Interna dos jogos e dos esportes, representados pelas Ações Motrizes, tendo como base os limites e as possibilidades determinadas pelos regulamentos.

O conceito de Ação Motriz tem um papel fundamental pois estabelece a especificidade da Praxiologia Motriz. Segundo Parlebas (1981), a Ação Motriz é o processo de adaptação da Conduta Motriz de um ou mais sujeitos ativos, em uma situação motriz particular. Consiste em todos os movimentos, independente de seus executores, realizados durante a prática de um jogo ou esporte, desde que previamente determinados pelas regras e normas de funcionamento da atividade. Parlebas (2001) resume essas ideias quando afirma que a Ação Motriz nasce e se desenvolve na matriz da Lógica Interna. Para melhor compreensão do conceito de Lógica Interna, o mesmo autor, em outro texto, relata um esclarecedor exemplo:

Admitimos que cada parte do handebol seja única; todos os encontros ludo-esportivos diferem uns dos outros; todos têm sua própria história e estão salpicados de acontecimentos originais. Não obstante, estas diferentes peripécias são resultantes de uma mesma matriz. Um jogo esportivo não é somente um puro fantasma entregado às extravagâncias subjetivas: é, antes de tudo, um corpo de regras. E esse corpo de regras irá impor sua regra ao corpo. Define as características objetivas do jogo, ou seja, sua lógica interna que irá gerar comportamentos, sem dúvida alguma diversos, mas todos marcados pelo mesmo carimbo (PARLEBAS, 1996, p. 16).

\footnotetext{
${ }^{2}$ Realidade complexa de natureza práxica em que todos os componentes que fazem parte da mesma ostentam a característica essencial de interagirem todos entre si. A Praxiologia vê os jogos como sistemas praxiológicos (LAGARDERA; LAVEGA BURGUÉS, 2003).
}

Movimento, Porto Alegre, v. 16, n. 01, p. 131-148, janeiro/março de 2010. 
Da mesma forma, a introdução do conceito da Conduta Motriz permitiu dar a coerência necessária à Educação Física, bem como proporcionar-lhe uma ferramenta metodológica em que os alunos são observados em sua totalidade e suas ações possuem significados e intencionalidades. Dessa forma, a Educação Física Escolar não trabalha com Ações Motrizes e sim com as Condutas Motrizes dos educandos. Define-se a Conduta Motriz como uma organização do comportamento motor mas com significados. O estudioso francês During (1992), em sua obra chamada "La Crise dês Pedagogies Corporalles" complementa essa ideia destacando que toda Conduta Motriz se manifesta por um comportamento motor mas não se reduz a este.

O autor utiliza essa terminologia com a intenção de delimitar a área de atuação da Educação Física Escolar, entendida por ele como um campo da pedagogia das Condutas Motrizes em que a intervenção pedagógica exerce influência direta nas Condutas Motrizes dos alunos, de acordo com as concepções epistemológicas do professor e as normas do sistema educativo. Este ponto nos leva a comentar, uma vez mais, que a Praxiologia Motriz não possui uma proposta pedagógica, muito menos se constitui em uma concepção de ensino. Não desconsiderando as inúmeras influências que o contexto exerce sobre as práticas motrizes, considera esses elementos constituintes de uma Lógica Externa. Essa, por sua vez, mesmo que intimamente interligada à Lógica Interna, pode ser interpretada fora da lógica específica de cada jogo ou esporte.

Um exemplo utilizado para explicar que a Praxiologia Motriz não se trata de uma concepção didático-pedagógica está relacionado com a linguística e a gramática. O professor de gramática deve estudar as regras gramaticais, possibilitando melhor entendimento da sua dinâmica para compreender o emprego correto dentro da língua. Porém, a maneira como esses conteúdos serão transmitidos aos seus alunos poderá ser de forma técnica e descontextualizada ou então mais crítica, com leituras e significados sociais. Pela ausência de uma concepção educacional, o conhecimento praxiológico deve ser mediado por alguma abordagem específica e, assim, integrar as áreas de conhecimento que fundamentam a práxis da Educação Física.

Movimento, Porto Alegre, v. 16, n. 01, p. 131-148, janeiro/março de 2010. 
Entre os temas abordados pela Praxiologia Motriz, um que tem extrema relevância para a Educação Física Escolar é a diferenciação entre esporte e jogo tradicional. Ambos, para Parlebas (1999), situações motrizes de confronto codificado, denominado jogo ou esporte pela instância social. O Jogo Esportivo Institucional, ou Esporte, possui uma organização representada por entidades, por associações e por federações que têm como objetivo padronizar as regras e formas de participação para adequá-lo às condições necessárias para o desenvolvimento do alto rendimento imposto, princípios estes fortemente influenciados por processos socioeconômicos e de consumo ligados aos eventos esportivos. Já o Jogo Esportivo Tradicional compreende todos os jogos esportivos que não tenham sido institucionalizados e estão atrelados a uma tradição de uma sociedade ou grupo específico. Também apresentam regras objetivas mas elas podem ser alteradas livremente, de acordo com o contexto em que se concretizam. São esses conceitos e parâmetros de análise, aqui apresentados, que na sequência serão relacionados com a concepção Crítico-Emancipatória do professor Elenor Kunz.

\section{Primeiras articulações da Praxiologia Motriz com a Concepção Crítico-Emancipatória}

Este texto introduz a discussão, como um primeiro passo, das contribuições da Praxiologia Motriz para a Concepção Crítico-Emancipatória, tendo, como ponto de partida, conceitos de esporte e jogo tradicional propostos por Pierre Parlebas e suas relações com as bases metodológicas propostas por Elenor Kunz.

No que trata do conceito restrito de esporte, as definições dos autores para as duas temáticas centrais desse estudo convergem para uma aproximação e entendimento do fenômeno esportivo como uma construção histórico-social e reflexo de inúmeras determinações. $\mathrm{O}$ professor Pierre Parlebas (2001) aponta várias características dos jogos esportivos para propor a distinção de esporte e jogo tradicional. A Praxiologia Motriz considera as influências que os princípios do esporte de alto rendimento exercem sobre a realidade escolar e reconhece sua hegemonia nesse contexto. Evidencia seu posicionamento em relação a esse tema na citação abaixo, quando diz que o esporte:

Movimento, Porto Alegre, v. 16, n. 01, p. 131-148, janeiro/março de 2010. 
Tornou-se a referência e o objetivo fundamental proposto pelas instituições oficiais que regem a prática do professor de Educação Física. Como reação tem se desenvolvido uma concepção que denuncia o esporte como atividade "alienante", porque as práticas estabelecidas não fariam mais que reproduzir os procedimentos de exploração e escravidão do indivíduo (exigências desumanas do treinamento, busca por medalhas, a mais alta politização das provas etc). $\mathrm{O}$ esporte tem se convertido em muito na imagem do antijogo. (PARLEBAS, 2001, p. 313).

Já o professor Elenor Kunz (1991) distingue o esporte quanto ao seu sentido e suas (im)possibilidades educacionais. Para a análise do esporte de rendimento, destaca dois princípios, conforme já apresentado, ou seja, o da sobrepujança e o das comparações objetivas. E como consequência de sua natureza, evidencia o processo de especialização precoce e o caso do doping como problemas enfrentados pelo âmbito esportivo. Essa negação do esporte não vai ao encontro da ideia de excluí-lo como conteúdo das aulas de Educação Física. Ao contrário, busca colaborar para que este assuma outros sentidos e seja transformado, tornando-se mais adequado a uma perspectiva pedagógica crítica.

Um dos pontos centrais da proposta Crítico-Emancipatória é a ideia de Transformação Didático-Pedagógica, em que o esporte de rendimento passa por um tratamento pedagógico. A definição de Jogo Esportivo Tradicional, feita por Parlebas, possui relações importantes com esse conceito proposto pela abordagem. Resumidamente, os jogos tradicionais consistem em todos os jogos esportivos que não foram institucionalizados, diferenciando-se dos jogos pré-desportivos, tão conhecidos em nossas aulas e que promovem uma adaptação dos esportes e a criação de jogos para facilitar a iniciação esportiva, uma prática completamente ligada à lógica do rendimento. Essa diferenciação quanto aos educativos pré-desportivos também é uma preocupação de Kunz ao definir seu conceito de esporte com finalidades educacionais - em que a transformação do esporte na escola desconsidera as instituições oficiais e suas determinações. Para melhor esclarecer esse tema, Parlebas (2001 apud RIBAS, 2002, p. 195) apresenta as características essenciais dos Jogos Esportivos Tradicionais, que são:

Movimento, Porto Alegre, v. 16, n. 01, p. 131-148, janeiro/março de 2010. 
vinculados a uma tradição de tempos passados; regidos por um corpo de regras flexíveis que admitem mudanças em função da vontade dos participantes; não dependem de instâncias oficiais e ignoram os processos socioeconômicos.

Muitos dos estudos da Praxiologia Motriz têm se dedicado a conhecer jogos tradicionais praticamente inexplorados, dotados de características únicas e extremamente mais complexas que a dos esportes, devido às inúmeras formas de participação existentes, que descaracterizam o equilíbrio necessário às comparações objetivas da prática esportiva institucionalizada. Em relação à diversidade do mundo dos jogos, Parlebas traz um exemplo interessante sobre as formas de participação:

Os jogos tradicionais oferecem uma paisagem muito mais desigual. Em muitos casos, os jogadores podem ser levados a mudar de equipe, convertendo-se seus adversários bruscamente em seus companheiros (rede instável); inclusive, às vezes, no caso de um dado participante, outro jogador é potencialmente, às vezes e no mesmo momento, companheiro e adversário (rede ambivalente). Esta incoerência relacional culmina no jogo paradoxo, repleto de coalizões e contra-coalizões, tão contraditórias como provisórias. No lugar de estar estreitamente submetido à lógica de uma equipe, frequentemente o jogador está livre para suas decisões motrizes, e pode não ter que prestar contas a ninguém. Esta total autonomia do participante em um jogo coletivo, desconhecida no esporte, não se encontra mais do que em certos jogos tradicionais. (PARLEBAS, 1988, p. 230)

A ideia de compreensão da Lógica Interna facilita a transferência de estruturas e lógicas de atividades, estimulando a criação de novas formas de jogar. Os aspectos originais dos jogos tradicionais, como demonstrado no exemplo acima, elucidam a existência de inúmeras peculiaridades e características não aproveitadas pelos esportes, muitas delas desconhecidas até o momento e que apontam a necessidade de novas investigações sobre o tema.

O processo de Transformação Didático-Pedagógica se inicia pela identificação do significado central do movimentar-se das modalidades,

Movimento, Porto Alegre, v. 16, n. 01, p. 131-148, janeiro/março de 2010. 
para que este permaneça inalterado, continuando-se, assim, a trabalhar com o respectivo conteúdo. Há mudanças no sentido individual e coletivo dado aos esportes na Educação Física Escolar. Essas mudanças no entendimento do esporte visam a uma busca de intencionalidade e contextualização do movimento nas aulas. Esse processo de transformação não acontece de forma sistemática e pré-determinada. O que existe nas inúmeras publicações são exemplificações de algumas possibilidades de mudanças.No entanto, muitas outras, ainda não aplicadas, podem ser transformadas e construídas com base no contexto e nas reflexões levantadas nas aulas.

De uma forma direta, mas não superficial, pode-se afirmar que, além da mudança no sentido da prática do esporte, algumas alternativas dessa metodologia se viabilizam pela alteração das regras e normas de funcionamento das atividades, abrindo a perspectiva de contribuições dos estudos sobre o conhecimento praxiológico nessa instância. No início do texto, foi destacado que a Praxiologia Motriz propõe instrumentos de análise para compreensão da Lógica Interna das práticas motrizes e tem o objetivo de tornar visíveis as características desses sistemas criados pelo conjunto de regras. Em um primeiro momento, estudar os tipos de interação, os processos de tomada de decisão, a configuração do meio ambiente, as funções dos jogadores e inúmeros outros tipos de análises, poderá auxiliar na identificação do significado central dos esportes, dos jogos e dos exercícios. Exemplificando: no ensino do voleibol, tem se utilizado, nas aulas de Educação Física Escolar, o jogo pré-desportivo conhecido como Newcomb ${ }^{3}$ (jogo em que, em vez de rebater a bola, os participantes devem segurá-la). Ao analisar essa atividade pela ótica da Praxiologia Motriz, observamos que sua Lógica Interna mantém elementos similares ao esporte voleibol (posicionamento em quadra, número de jogadores, local, pontuação etc), que deveriam, em tese, facilitar o aprendizado da modalidade. Entretanto, quando os alunos passam à prática do voleibol padrão,

\footnotetext{
${ }^{3}$ Também conhecido como Newcom ou corruptelas, de acordo com Paul (1996), este jogo foi inventado pela professora Clara Gregory Baer da Escola Sophie Newcomb de Nova Orleans, Estados Unidos. Foi pensado para ser jogado por meninos e meninas, homens e mulheres no ano de 1895 mas somente na década de 20 tornou-se atividade competitiva e parte do conteúdo escolar das escolas americanas. O autor levanta uma importante questão neste artigo: Teria Willian Morgan, idealizador do voleibol no mesmo ano, utilizado a ideia do jogo do Newcomb para elaborar o voleibol?
}

Movimento, Porto Alegre, v. 16, n. 01, p. 131-148, janeiro/março de 2010. 
enfrentam dificuldades para desenvolver muitos daqueles elementos, perdendo completamente a dinâmica antes conseguida. Isso se deve, principalmente, à perda de uma das características centrais da modalidade que é a ação de rebater com características de cooperação (ex.: passe e levantamento) e oposição (ex.: saque e ataque), características essas que, na concepção Crítico-Emancipatória, podem ser identificadas como o significado central do movimentar-se no voleibol. Constatada essa incoerência, o esporte voleibol e até mesmo o jogo Newcomb podem passar pela Transformação Didático-Pedagógica para superar esses equívocos e atender aos interesses de um ensino CríticoEmancipatório.

Em um segundo momento, na problematização dos esportes promovida pelo professor, o debate de alguns elementos praxiológicos pode ajudar a ampliar o conhecimento do aluno, criar critérios para compreensão da lógica dos jogos esportivos e utilização de uma gramática específica para que, em conjunto com o grande grupo (professor/ alunos), possam, com base nessas contribuições, adquirir informações, destrezas e estratégias para agir dentro do contexto esportivo. Mais uma vez, usaremos o esporte voleibol para exemplificar como a gramática do jogo e o conhecimento praxilógico, mediados pelo professor, podem contribuir para o ensino crítico-emancipatório. Exemplificando: O saque, um dos fundamentos mais importantes do voleibol, é muitas vezes, ensinado através de exercícios educativos que visam à utilização de estratégias e procedimentos para a reprodução das técnicas específicas. Entretanto, ao proporcionar ao educando a prática do jogo, nota-se a inexistência de intencionalidade tática, ou seja, o saque tem como ideia central colocar a bola na quadra adversária. Então, fazendo uso de conceitos de Oposição e Cooperação (comunicação práxica), o aluno é levado a compreender o saque não mais como um momento individual mas como uma ação que estabelece uma relação de oposição com a outra equipe, percebendo a necessidade de realizar leituras de informações e os processos de tomada de decisão. Por outro lado, se à proposta de transformação do voleibol agregarmos a ideia de que o saque deverá ter o objetivo de facilitar a ação do adversário - norma implícita em muitos encontros lúdicos de voleibol, com participantes de diferentes níveis de ações motrizes que pactuam que o saque deve

Movimento, Porto Alegre, v. 16, n. 01, p. 131-148, janeiro/março de 2010. 


\section{Artifor Orifinais Gil T. Oliveira e João Francisco M. Ribas}

ser facilitado (normalmente por baixo) - a ação de oposição é substituída pela ação de cooperação, onde o objetivo do saque será de facilitar a ação dos passadores. Assim, cada transformação pedagógica do esporte, que normalmente implica na re-elaboração das regras e formas de atuação, também será situada em sua lógica de funcionamento com base na Praxiologia, destacando os principais elementos para os processos metodológicos. De uma forma simples e contextualizada, os processos de leitura, de tomada de decisão e de aprimoramento das ações motrizes são desenvolvidas a partir de uma necessidade e problema gerados pela dinâmica da atividade. Entendemos, assim, a relevante contribuição da Praxiologia Motriz para o desenvolvimento da competência objetiva, pois, segundo Kunz (2004), com a melhoria das habilidades práticas o aluno pode aumentar, também, o seu espaço e suas possibilidades de autodeterminação e determinação nas atividades de ensino.

Essa transformação nos esportes deve ter como centro o aluno e o contexto escolar e não a modalidade esportiva. Consequentemente, utiliza-se esse recurso pedagógico devido às limitações físicas e técnicas dos educandos em realizar os movimentos pelo modelo do alto rendimento, tendo como objetivo tornar a prática atrativa para que assim possam adquirir experiências de movimentos esportivos que normalmente só um atleta conseguiria. É fundamental perceber que a técnica deve ser considerada um meio para atingir fins, portanto, a técnica deve ser sempre subordinada às finalidades educacionais. $\mathrm{O}$ desenvolvimento dos gestos padrões pode até ser atingido mas não compreende o objetivo central da Educação Física Escolar. Ou seja, praticamente a maioria dos alunos nunca poderá jogar como os atletas de ponta mas eles podem encenar, criar o seu esporte e, principalmente, construir, de forma consciente e crítica, essas vivências.

A encenação esportiva permite a interpretação e compreensão dos diferentes papéis existentes no esporte, representando, por exemplo, os praticantes, os juízes, os torcedores, os técnicos, entre outros, chegando até a promover a reflexão sobre a ligação dos esportes com os processos socioeconômicos e de consumo. A Praxiologia Motriz, num exemplo simples, pode ajudar os educandos a compreender as alterações na Lógica Interna dos esportes e perceber suas evoluções

Movimento, Porto Alegre, v. 16, n. 01, p. 131-148, janeiro/março de 2010. 
históricas. Porém, um dos principais esclarecimentos da Praxiologia Motriz para a abordagem Crítico-Emancipatória é o uso de uma gramática própria para o universo dos jogos e esportes. Com essa proposta, não se pretende acrescentar termos completamente inerentes à realidade dos alunos, pois a maioria desses conceitos possui uma fácil compreensão, podendo ser adaptados ao contexto onde se concretizam as aulas de Educação Física, construindo conjuntamente com os alunos uma linguagem pela qual eles possam se expressar sobre os jogos e esportes que vivenciam e mostrando que a linguagem é essencial, porque interliga as outras categorias: trabalho e interação - já que, sem comunicação, não pode haver nenhum tipo de interação. A importância da Praxiologia Motriz para a Educação Física se evidencia por todas as aproximações e exemplos citados nesse estudo e, principalmente, a questão da gramática dos jogos e esportes para a sua transformação didática na afirmação de Kunz, que diz que

\begin{abstract}
"em síntese, as competências comunicativas e interativas no ensino escolar desenvolvem-se a partir da ativa participação de sujeitos socializados e dotados de determinadas comunicação e expressão". (KUNZ, 2004, p. 145)
\end{abstract}

\title{
5 CONSIDERAÇÕES FINAIS
}

Resumidamente, foram demonstrados vários conceitos e parâmetros de análise da Praxiologia Motriz sobre os jogos e esportes, onde entendemos que seja importante destacar que esses critérios praxiológicos, como aqui defendido, não devem ser tratados como elementos fixos e imutáveis - quando confrontados com uma realidade deverão ser redimensionados. No que trata da metodologia Crítico-Emancipatória, recursos didáticos como a Transformação Didático-Pedagógica do esporte e a encenação esportiva mostraram importantes relações com os Jogos Esportivos Tradicionais, em que estas práticas recebem tratamento pedagógico de acordo com a realidade escolar em que se concretizam. Nessas relações, apontaram-se relevantes contribuições da Praxiologia Motriz no que diz respeito à compreensão e à construção da ideia de Lógica Interna e também da formulação de uma gramática específica dos jogos e esportes, para que possa desvelar novas possibilidades no processo de reconstrução didática das práticas motrizes e

Movimento, Porto Alegre, v. 16, n. 01, p. 131-148, janeiro/março de 2010. 
proporcionar, assim, um melhor desenvolvimento das competências objetiva, social e comunicativa. Esse conhecimento se constitui como um elemento a mais para dar novos significados às nossas práticas pedagógicas mas de forma alguma resolve todos os problemas de nossa área.

Por fim, torna-se importante destacar que, ao realizar os primeiros diálogos teóricos também neste caminho, nos deparamos com novas dúvidas à medida que o estudo foi sendo produzido. Com base nas relações feitas neste estudo, acredita-se que é viável a aproximação entre a Concepção Crítico-Emancipatória e a Praxiologia Motriz. Contudo, é necessário prudência para não tornar essa ligação superficial e inconsistente, tampouco alterar os fundamentos da abordagem em questão. E fica, com este texto, nosso compromisso de colocar em prática essas relações, em uma prática pedagógica que nos permita avançar ainda mais neste complexo processo de aproximação entre estes relevantes conhecimentos da Educação Física.

Movimento, Porto Alegre, v. 16, n. 01, p. 131-148, janeiro/março de 2010. 


Articulations of the Motor Praxiology with the
Critical-Emancipatory approach
Abstract: This work is a theoretical analysis of the con-
ceptual design of the Praxiologia Motriz and Critical-
emancipatory conception, developing and setting some
elements of the Theory of Action Motriz, maintaining the
commitment to an education emancipator. Research re-
sults indicate the contributions of the Motor Praxiology
for the comprehension of the internal logic and the creation
of a grammar of sports games and making the process
of understanding the core meaning of "move" as well as
the construction of "communicative action".
Keywords: Sports. Sociology: education. Concept
formation. Professional competence.

Articulaciones de la Praxiología Motriz con el abordaje Crítico-Emancipatoria

Resumen: El presente trabajo consiste en un análisis teórica conceptual de la Praxiología Motriz y de la concepción Crítico-Emancipadora, desarrollando y situando algunos elementos de la Teoría de la Acción Motriz, manteniendo el compromiso con una enseñanza emancipadora. Los resultados de la investigación apuntan para contribuciones de la Praxiología Motriz en el sentido de la comprensión de la Lógica Interna y la creación de una gramática de los juegos y deportes viabilizando el proceso de entendimiento del significado central del "se movimentar", así como de en la construcción del "agir significativo".

Palabras clave: Deportes. Sociologia: educación. Formacióm de concepto. Competencia profesional.

\section{REFERÊNCIAS}

BUSSO, Gilberto Leandro; VENDITTI, Rubens. Sistematização epistemológica da educação física brasileira: concepções pedagógicas crítico-superadora e críticoemancipatória. Revista Digital; Buenos Aires, v. 10, n. 83, abr. 2004. Disponível em: <http://www.revistadigital.com.br>. Acesso em: 22 nov. 2005

DURING, Bertrand. La crisis de las pedagogias corporales. Málaga: Unisport, 1992.

KUNZ, Elenor. Educação Física: ensino \& mudanças. ljuí: Ed. Unijuí, 1991.

Esclarecimento e emancipação: pressupostos de uma teoria educacional crítica para a Educação Física. Movimento, Porto Alegre, n. 10, p. 35-39, jan. 1999.

Movimento, Porto Alegre, v. 16, n. 01, p. 131-148, janeiro/março de 2010. 
148 Artigos Originais Gil T. Oliveira e João Francisco M. Ribas 2004 Transformação didático-pedagógica do esporte. 6. ed. ljuí: Ed. Unijuí,

LAGARDERA OTERO, Francisco; LAVEGABURGUÉS, Pere. Introdución a la praxiología motriz. Barcelona: Paidotribo, 2003.

PARLEBAS, Pierre. Contribuition a un léxique continente en science de action motríce. Paris: INSEP, 1981.

Elementos de sociologia del deporte. Málaga: Unisport, 1988.

Los universales de los juegos desportivos. Revista de Praxiologia Motriz, Las Palmas de Gran Canária, v.1, n. 0, p. 15-30. 1996.

Jeux, sports et sociétés: lexique de praxéolgie motrice. Paris: Institut du sport et del éducation physique, 1999

Juegos, deporte y sociedad: léxico de praxiología motriz. Barcelona: Paidotribo, 2001

PAUL, Joan. A lost Sport: Clara Gregory Baer and Newcomb Ball. Journal of Sport History, Los Angeles, v. 23, n. 2, 1996. Disponível em: <http://www.la84foundation.org/ SportsLibrary /JSH/JSH1996/JSH2302/jsh2302f.pdf Acesso em: 16 jan. 2009.

RIBAS, João Francisco Magno. Contribuições da praxiologia motriz para a educação física escolar: ensino fundamental. 2002. 241 f.. Tese (Doutorado) Faculdade de Educação Física, UNICAMP. Campinas, 2002.

Praxiologia Motriz. In: GONZÁLEZ, Fernando Jaime; FENSTERSEIFER, Paulo Evando (Org.). Dicionário crítico de educação física. ljuí: Ed. Unijuí, 2005.

RIBAS, João Francisco Magno (Org.) Jogos e esportes: fundamentos e reflexões da praxiologia motriz. Santa Maria: Editora da UFSM, 2008.

Movimento, Porto Alegre, v. 16, n. 01, p. 131-148, janeiro/março de 2010. 